\title{
COVID-19 and Solid Organ Transplantation: Role of Anti-SARS-CoV-2 Monoclonal Antibodies
}

\author{
Abhay Dhand ${ }^{1}\left[\right.$ [D $\cdot$ Raymund R. Razonable ${ }^{2}$ (i) \\ Accepted: 8 November 2021 / Published online: 15 January 2022 \\ (c) The Author(s), under exclusive licence to Springer Nature Switzerland AG 2022
}

\begin{abstract}
Purpose of Review Solid organ transplant recipients (SOTRs) are ideal candidates for early treatment or prevention of coronavirus disease 2019 (COVID-19) using anti-SARS-CoV-2 monoclonal antibodies because of multiple underlying medical conditions, chronic immune-suppression, sub-optimal immunogenic response to vaccination, and evolving epidemiological risks. In this article, we review pertinent challenges regarding the management of COVID-19 in SOTRs, describe the role of active and passive immunity in the treatment and prevention of COVID-19, and review real-world data regarding the use of anti-SARS-CoV-2 monoclonal antibodies in SOTRs.

Recent Findings The use of an anti-SARS-CoV-2 monoclonal antibody in high-risk solid organ transplant recipients is associated with a reduction in the risk of hospitalization, need for intensive care, and death related to COVID-19. Overall, the early experiences from a diverse population of solid organ transplant recipients who were treated with anti-spike monoclonal antibodies are encouraging with no reported acute graft injury, severe adverse events, or deaths related to COVID-19.

Summary Anti-SARS-CoV-2 antibodies are currently authorized for treatment of mild-moderate COVID-19 and post-exposure prophylaxis, including in SOTRs. Potential future uses include pre-exposure prophylaxis in certain high-risk persons and synergistic use along with emerging oral treatment options. Successful timely administration of anti-SARS-CoV-2 monoclonal antibodies requires a multidisciplinary team approach, effective communication between patients and providers, awareness of circulating viral variants, acknowledgement of various biases affecting treatment, and close monitoring for efficacy and tolerability.
\end{abstract}

Keywords COVID-19 · Monoclonal antibody · Passive immunity · Transplant · Coronavirus

\section{Introduction}

Severe acute respiratory syndrome virus 2 (SARS-CoV-2) emerged as a human pathogen in December 2019. As of October 22, 2021, this global pandemic had affected 240 million people worldwide resulting in nearly 5 million deaths

This article is part of the Topical Collection on COVID-19 and Transplantation

Abhay Dhand

Abhay.dhand@wmchealth.org

1 Transplant Infectious Diseases, Department of Medicine and Surgery, ACP-Transplant Center, Westchester Medical Center/New York Medical College, 100 Woods Road, Valhalla, NY 10595, USA

2 Division of Infectious Diseases, Department of Medicine and the William J von Leibig Center for Transplantation and Clinical Regeneration, Mayo Clinic, Rochester, MN, USA [https://coronavirus.jhu.edu/data. Accessed October 20, 2021]. Almost 20 months into the pandemic, we have seen tremendous progress in epidemiological tracking, diagnosis, prevention, and treatment of coronavirus disease 2019 (COVID-19). Here, we review pertinent challenges in managing COVID-19 in solid organ transplant recipients (SOTRs), assess the role of active and passive immunity in the treatment and prevention of COVID-19, review real-world data regarding the use of anti-SARS-CoV-2 monoclonal antibodies in SOTRs, and discuss their potential role in the future.

\section{Impact of COVID-19 on Solid Organ Transplant Recipients}

Solid organ transplant recipients (SOTRs) are at a higher risk of developing severe COVID-19 because of the preponderance of medical comorbidities (diabetes, hypertension, chronic kidney disease, increased body mass index) 
along with impaired immunity due to chronic immune suppression [1]. Once hospitalized, SOTRs with COVID-19 when compared to non-COVID-19-related admission had higher rates of need for intensive care (adjusted odds ratio [aOR]: 2.12), mechanical ventilation (aOR: 3.75 ), cardiac arrest (aOR: 4.05), and need for renal replacement therapy (aOR: 1.25) [2]. In a cohort of 17,012 hospitalized adult SOTRs during the period of April 1, 2020, to November 30,2000 , the excess mortality was 2.5 -fold higher when compared to hospitalized SOTRs with non-COVID-19 pneumonia [2]. As the transplant community became familiar with the management of COVID-19, the 28-day mortality among SOTRs hospitalized with COVID-19 decreased from $19.6 \%$ in early 2020 to $13.7 \%$ in late 2020 , although the rate remains alarming high. In a large multicenter registry, this decline was associated with lower rates of hospitalization (58.9\% vs. $75.8 \%$ ), decreased incidence of infection in black patients (30\% vs. $42 \%$ ), decreased incidence in kidney transplant recipients (56\% vs. 67\%), and increased use of various therapeutic agents like corticosteroids and remdesivir [3]. Data from the national COVID-19 cohort collaborative found COVID-19 associated graft loss in $28(1.5 \%$, OR: 79.97$)$ of all 18,121 adult SOT recipients from January 1, 2020, to November 20, 2020 [4]. The high rates of mortality despite the availability of remdesivir suggest the need for better therapies and strategies, such as the use of active and passive immunization for prevention and treatment.

\section{Active Immunity Through Vaccination and Its Limitations in Transplant Recipients}

The scientific community worked collaboratively to develop COVID-19 vaccines in record time, and the first vaccines were authorized for the prevention of COVID-19 starting in December 2020 [5]. Because the SOTRs were considered "high risk," they were given priority for vaccination during the early part of the rollout. However, it has since been demonstrated that SOTRs mount a sub-optimal humoral response to COVID-19 vaccination. Among 658 adult SOTRs who received 2 doses of SARS-CoV-2 mRNA vaccine, 357 (54\%) had measurable antibody response, while $301(46 \%)$ has no antibody response 2 weeks after the vaccination [6]. This limited antibody response was associated with the use of anti-metabolite immunosuppression. Similar additional studies have shown a variable antibody response in adult solid organ transplant recipients $[7,8]$. Risk factors associated with sub-optimal response were the age of recipient $>60$ years, shorter time from transplantation, higher immunosuppression with use of three agents, use of anti-metabolite agents, and diabetes mellitus. Sub-optimal antibody response to vaccination in SOTRs is associated with an 82-fold higher risk of breakthrough COVID-19 and 485-fold higher risk of associated hospitalization and death when compared to the cumulative US population [9•]. Among 18,215 fully vaccinated (14 days after recommended dose/s, non-booster) from 17 transplant centers, breakthrough infection occurred in 151 $(0.83 \%)$ resulting in hospitalization in $87(0.48 \%$, range $0.23-2.25)$ and death in $14(.077 \%)$ patients [9•].

The administration of additional (3rd) dose strategies of the COVID-19 mRNA vaccine has been implemented to improve vaccine immunogenicity $[10,11 \bullet \bullet, 12]$. Among $60 / 120$ adult SOTRs, the third dose of mRNA vaccine when compared to placebo was considered safe and was associated with an increase in the percentage of patients with anti-receptor-binding domain antibody of at least $100 \mathrm{U}$ per milliliter (55\% vs. $18 \%)$, median percent viral neutralization (71\% vs 13\%), and greater specific T-cells (432 vs 67 cells per $10^{6} \mathrm{CD} 4+\mathrm{T}$-cells) [13]. These data suggest that even a third dose of vaccination may not lead to protective immunization of SOTRs, and thus, additional strategies will need to be implemented to protect these vulnerable patients from COVID-19. This could include a cautious minimization of immunosuppression in select patients and/or the potential use of passive immunization.

\section{Passive Immunity for the Prevention and Treatment of Infections}

Passive immunity, or the administration of immune proteins or antibodies, is used for the treatment of various infections. These antibodies are generally identified and derived from the convalescent plasma of patients who have recovered from an acute illness. The antibody-based therapies are highly specific, have low toxicity, and are efficacious especially when given early in the course of the disease-this emphasizes the need for a rapid diagnosis and an easy access to these therapies [13]. In the intact antibody, Fab is the variable region that binds to the antigen and $\mathrm{Fc}$ is the constant region that determines the biological properties such as its half-life, interaction with $\mathrm{Fc}$ receptors, activation of the complement system, and possibly triggering adverse drug events. The Fc portion can be modified to change the properties like prolonging the half-life of various antibodies (from 21 up to 85 days), enhancing or diminishing effector function, and increasing mucosal penetration [14].

Passive immunity was first used in the 1890s to protect against bacterial toxins [15]. Since then, passive antibody therapy has been used for prophylaxis and treatment of various viral infections including rabies, hepatitis A, hepatitis B, varicella-zoster virus, and respiratory syncytial virus pneumonia. More recently, passive immunization has been used 
in various epidemics including severe H1N1 2009 influenza, 2013 West African Ebola epidemic, H5N1, and H7N9 avian influenza outbreaks [13, 14]. Experiences from previous coronavirus outbreaks also showed that neutralizing antibodies are present in the sera from persons who have recovered from the infection [16]. This prompted the use of COVID19 convalescent plasma (CCP) during the early period in the pandemic, but studies on its safety and efficacy have shown variable outcomes [17].

Plasma and B-cells of patients who had recovered from COVID-19 were searched for neutralizing antibodies against the virus, and this eventually led to the development of monoclonal antibodies for its management [18]. A combination of different antibodies (termed antibody cocktails) has the promise to provide a synergistic effect in terms of neutralization and minimize the probability of escape viral mutants. Within the cocktail therapies, antibodies binding to two different non-competing epitopes of the virus target help sustain the efficacy of antibody treatment. Similarly, a broadly neutralizing pan-virus family antibody, which binds to a conserved region of different coronaviruses, would also maintain activity against emergent variants. Practical use of passive immunity using antibody therapies is limited by the high cost of production, storage, and administration challenges.

\section{Anti-SARS-CoV-2 Monoclonal Antibodies}

The spike (S) protein on SARS-CoV-2 is the primary antigenic epitope which mediates virus-host cell membrane fusion and subsequent viral entry into the human cells [19]. Therefore, antibodies against the receptor-binding domain of the spike protein-spike antibodies work by neutralizing the ability of the virus to attach and invade human cells. Several anti-SARS-CoV-2 monoclonal antibodies have received Emergency Use Authorizations (EUAs) from the Food and Drug Administration (FDA) for the treatment of COVID19 as well as post-exposure prophylaxis [https://www.covid 19treatmentguidelines.nih.gov/therapies/anti-sars-cov-2antibody-products/anti-sars-cov-2-monoclonal-antibodies/ Accessed October 20, 2021] [20-22]. This data along with key characteristics of these antibodies are summarized in Table 1.

\section{Clinical Indications}

Treatment of Mild-Moderate COVID-19 As of October 2021, FDA EUA allows for use of casirivimab-imdevimab (C-I), bamlanivimab-etesevimab (B-E), and sotrovimab for treatment of mild-moderate COVID-19 in non-hospitalized patients with laboratory-confirmed SARS-CoV-2 infection who are at high risk of progression to severe disease and/or hospitalization. Treatment with these monoclonal antibodies should be started as soon as possible after a positive SARSCoV-2 antigen or nucleic acid amplification test (NAAT) result and within 10 days of symptom onset. Monoclonal antibodies can also be used in patients who are hospitalized for other conditions and still meet the FDA EUA use criteria. They are not currently approved for use in patients who are hospitalized with severe COVID-19. Because of decreased activity against the beta and gamma variants, the use of B-E is only recommended in regions where the combined frequency of potentially resistant variants is low $(<5 \%)$. C-I can also be given via subcutaneous injection if intravenous infusions are not feasible or may delay treatment.

Post-exposure Prophylaxis As of October 2021, FDA EUA allows for use of C-I and B-E for post-exposure prophylaxis (PEP). PEP is indicated in individuals who are not fully vaccinated or who are not expected to mount an adequate immune response to complete SARS-CoV-2 vaccination (including individuals with immunocompromising conditions, those taking immunosuppressive medications) and have been exposed to an individual infected with SARSCoV-2 consistent with close contact or who are at high risk of exposure to an individual infected with SARS-CoV2 because of occurrence of SARS-CoV-2 infection in other individuals in the same institutional setting (for example, nursing homes, prisons). PEP should be administered as soon as possible and preferably within 7 days of high-risk exposure. The current criteria for identifying high-risk individuals include older age (age $\geq 65$ years), weight (adults with body mass index BMI $>25 \mathrm{~kg} / \mathrm{m}^{2}$, or if age $12-17$, have BMI $\geq 85$ th percentile for their age and gender based on CDC growth charts), pregnancy, chronic kidney disease, diabetes mellitus, immunosuppressive disease or immunosuppressive treatment, cardiovascular disease (including congenital heart disease or hypertension), chronic lung diseases, interstitial lung disease, cystic fibrosis and pulmonary hypertension, sickle cell disease, neurodevelopmental disorders (for example, cerebral palsy) or other conditions that confer medical complexity (genetic or metabolic syndromes and severe congenital anomalies), and having a medical-related technological dependence (tracheostomy, gastrostomy, or positive pressure ventilation (not related to COVID-19)).

\section{Monoclonal Antibody Preparations}

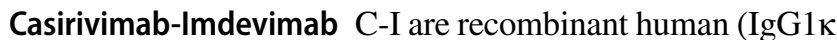
and $\operatorname{IgG} 1 \lambda$, respectively)-neutralizing monoclonal antibodies that bind to nonoverlapping epitopes of the spike protein receptor-binding domain (RBD) of SARS-CoV-2, thus blocking the attachment and subsequent entry of SARSCoV-2 into the human cells [23]. In double-blind, phase 3 


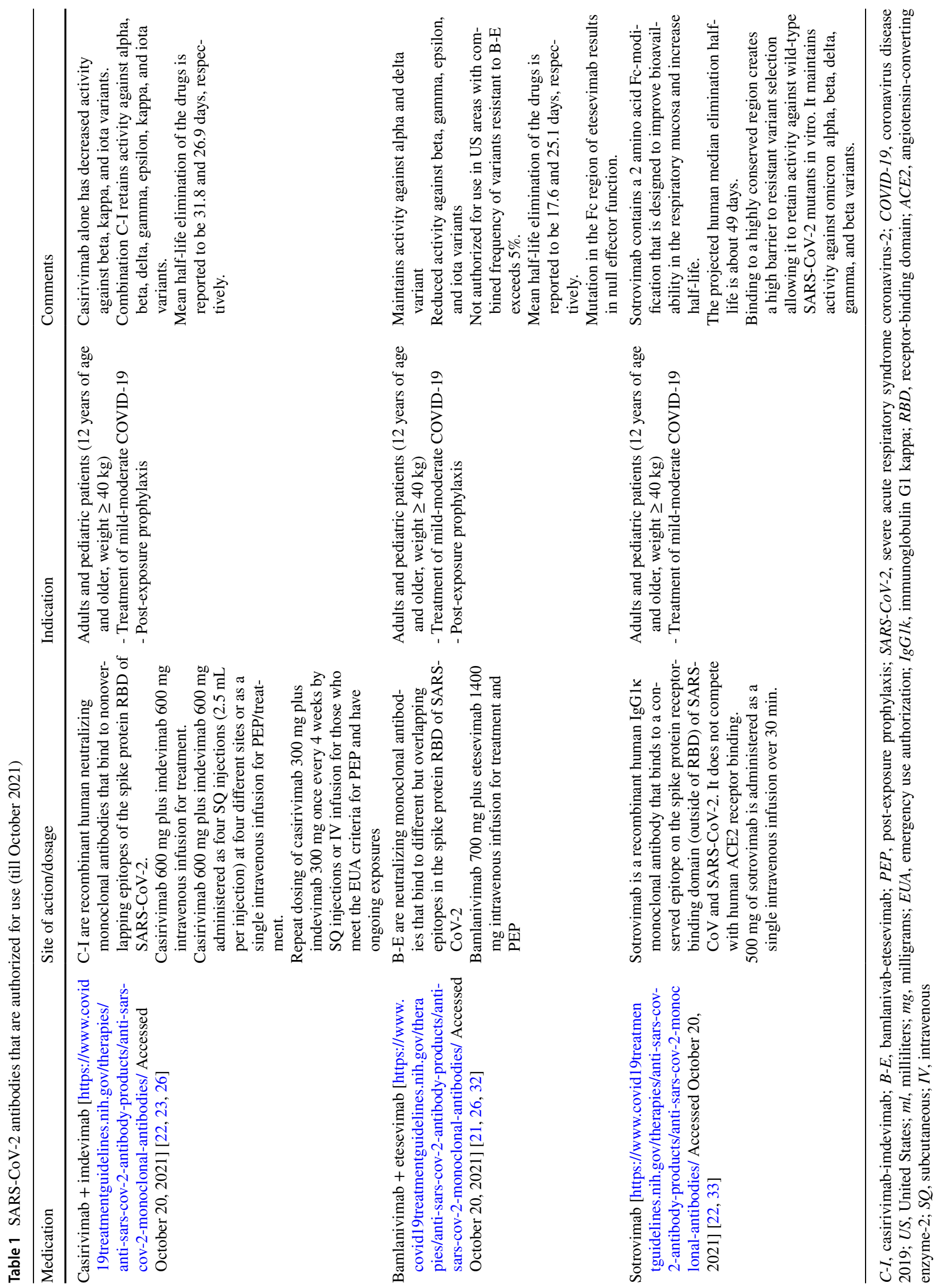


RCTs in outpatients with mild to moderate COVID-19, a single infusion of C-I 600-600 mg or 1200-1200 mg administered within 7 days of symptom onset when compared to placebo was associated with $2.2-3.3 \%$ absolute reduction and $70-71 \%$ relative risk reduction respectively in COVID19-related hospitalizations or all-cause death. C-I reduced the median time to symptom improvement to 5 days compared to 11 days for patients in the placebo arm [24]. Subcutaneous administration of C-I in household contacts of individuals with COVID-19 decreased the risk of progression to symptomatic disease by $80 \%$ in SARS-CoV-2-negative subjects and by $31 \%$ in SARS-CoV-2-positive subjects. Injection site reactions were observed in $12 \%$ of the $729 \mathrm{C}-\mathrm{I}$ participants [25].

Bamlanivimab-Etesevimab B-E are neutralizing human IgG1 k monoclonal antibodies that bind to different but overlapping epitopes in the spike protein RBD of SARS-CoV-2 and act by blocking the attachment and entry of SARSCoV-2 into the human cells. In double-blind, phase $3 \mathrm{RCT}$ in outpatients with mild to moderate COVID-19 who were at high risk for progressing to severe COVID-19, a single infusion of B-E (2800-2800 mg) given within 3 days of a positive virological test when compared to placebo showed $4.8 \%$ absolute reduction and $70 \%$ relative reduction in COVID-19-related hospitalizations or all-cause death. There was a significant reduction in viral load on days 3, 7, and 11 of treatment [26]. Residents and staff of 74 skilled nursing and assisted living facilities with no history of COVID19 received bamlanivimab within 7 days of at least one confirmed SARS-CoV-2-positive test in their facility. The treatment arm when compared to placebo showed a lower incidence of mild or worse COVID-19 (8.5\% vs $15.2 \%$ ) in all study subjects with a more pronounced reduction in facility residents (8.8\% vs. $22.5 \%)$. Four patients in the placebo arm and none in the treatment arm died of COVID-19 [27]. This data from the BLAZE-2 study for use of bamlanivimab alone was extrapolated to provide authorization for use of B-E as post-exposure prophylaxis.

Sotrovimab Sotrovimab is a recombinant human $\mathrm{IgG} 1 \kappa$ monoclonal antibody that binds to a conserved epitope on the spike protein receptor-binding domain (outside of RBD) of SARS-CoV and SARS-CoV-2. It does not compete with human ACE2 receptor binding. In a double-blind, phase $1 / 2 / 3$ randomized controlled trial (RCT) in outpatients with mild to moderate COVID-19, participants received a single dose of $500 \mathrm{mg}$ sotrivimab vs. placebo. Severely immunocompromised patients were excluded from this study. Participants who received sotrovimab when compared to placebo showed an $85 \%$ relative risk reduction in all-cause hospitalizations or death $[22,28 \bullet \bullet]$.

\section{Anti-SARS-CoV-2 Monoclonal Antibody in Solid Organ Transplant Recipients}

Based on multiple underlying medical conditions and chronic immune suppression, sub-optimal immunogenic response to vaccination and constantly evolving epidemiological risks, SOTRs are ideal candidates for early treatment or prevention using anti-SARS-CoV-2 monoclonal antibodies. While immunocompromised patients were minimally represented or were completely excluded in the clinical trials, they were included in the high-risk category of patients authorized for treatment as per the FDA. Subsequently, real-world data regarding the use of SARS-CoV-2 monoclonal antibodies in SOTRs is emerging [29••, 30-37]. This data is summarized in Table 2. None of these studies are randomized trials as these monoclonal antibodies were incorporated in the treatment guidelines of various healthcare facilities after their initial authorization by FDA in November 2020. These studies were all retrospective and often have no comparators, historical comparators, or comparators who did not receive monoclonal antibodies for various reasons-hence, all these studies have inherent biases that require caution when interpreting their findings. In the early studies, bamlanivimab monotherapy was the earliest and most commonly used monoclonal antibody for the treatment of mild-moderate COVID-19 [29••, 31, 34, 35]. Because of its decreased activity against various emerging variants, its FDA authorization has been revoked. The use of casirivimab-imdevimab increased after their initial approval and in the setting of the emergence of SARS-CoV-2 variants [30, 32]. This clinical data, along with the knowledge of the preserved in vitro activity of C-I, B-E, and sotrovimab against circulating predominant variants, can help identify the potential strengths and weaknesses of various available monoclonal antibody options and their future use [38]. These studies also address specific issues pertinent to SOTRs regarding the safety of infusion, risk of acute allograft rejection, and possible immune activation. Overall, monoclonal antibody administration was well tolerated, and no significant events of acute allograft rejection, exaggerated immune responses, anaphylaxis, or other serious transfusion-associated adverse events were noted. A higher viral burden in immunocompromised patients may increase the risk of emergence of resistant variants. While this was not reported in any of these studies, appropriate and early use of these monoclonal antibodies could help mitigate that risk.

Data regarding the treatment of mild-moderate COVID-19 with monoclonal antibodies show that SOTRs have multiple medical conditions that are associated with the risk of progression/hospitalization. The use of monoclonal antibodies in these study cohorts was associated with a low risk of emergency department visits, hospitalizations, mechanical ventilation, and need for intensive 
Table 2 Clinical data for use of anti-SARS-CoV-2 antibodies in solid organ transplant recipients

\begin{tabular}{|c|c|c|c|c|c|}
\hline Study & Medication & Patients & $\begin{array}{l}\text { Mean time from } \\
\text { symptoms- infusion } \\
\text { (days) }\end{array}$ & Outcomes & Comments \\
\hline $\begin{array}{l}\text { Yetmar et al. }[28 \bullet \bullet] \\
\text { US-various sites (Mayo) } \\
11 / 2020-01 / 2021\end{array}$ & $\begin{array}{l}\text { BAM (55) } \\
\text { C-I (18) }\end{array}$ & $\begin{array}{l}41 \mathrm{KT}+4 \mathrm{~K} / \mathrm{P}+13 \mathrm{LT} \\
+11 \mathrm{HT}+1 \mathrm{H} / \mathrm{L}+2 \mathrm{~L} \\
+1 \mathrm{P}\end{array}$ & 4 & $\begin{array}{l}\text { Follow-up: } 28 \text { days } \\
\text { ED visit } 11(15 \%) \\
\text { Hospitalization } 9 \\
\text { (7-COVID related } \\
9.5 \%) \\
\text { MV: } 0 \% \\
\text { Mortality: } 0 \%\end{array}$ & $\begin{array}{l}\text { Programmatic approach- } \\
\text { MATRx } \\
\text { Hospitalization was asso- } \\
\text { ciated with HTN, longer } \\
\text { time from symptoms to } \\
\text { infusion (6 d vs } 4 \mathrm{~d}) \\
\text { Well tolerated } \\
\text { No allograft rejection }\end{array}$ \\
\hline $\begin{array}{l}\text { Dhand et al. }[29 \bullet \bullet] \\
\text { US-New York } \\
\text { 12/2020-01/2021 }\end{array}$ & C-I (25) & $\begin{array}{l}17 \mathrm{KT}+3 \mathrm{LT}+3 \mathrm{HT}+ \\
2 \mathrm{H} / \mathrm{K}\end{array}$ & 2.5 & $\begin{array}{l}\text { Mean follow-up: } 22 \\
\quad(14-27) \text { days } \\
\text { Hospitalization: } 0 \% \\
\text { Mortality: } 0 \%\end{array}$ & $\begin{array}{l}\text { Well tolerated } \\
\text { Programmatic approach } \\
\text { No allograft rejection }\end{array}$ \\
\hline $\begin{array}{l}\text { Dhand et al. [30] } \\
\text { US-New York } \\
11 / 2020-12 / 2020\end{array}$ & BAM (10) & $6 \mathrm{KT}+2 \mathrm{LT}+1 \mathrm{HT}$ & 3.3 & $\begin{array}{l}\text { Mean follow-up: } 41 \\
\text { (14-69) days } \\
\text { Hospitalization: } 0 \% \\
\text { Mortality: } 0 \%\end{array}$ & $\begin{array}{l}\text { Well tolerated } \\
\text { Programmatic approach } \\
\text { No allograft rejection }\end{array}$ \\
\hline $\begin{array}{l}\text { Liu et al. [31] } \\
\text { US-New York } \\
01 / 2021-06 / 2021\end{array}$ & C-I (14) & $14 \mathrm{KT}$ & 5 & $\begin{array}{l}\text { Follow-up: } 30 \text { days } \\
\text { Hospitalization: } 2 / 14 \\
\quad(14 \%)-\text { COVID related } \\
\text { MV: } 0 \% \\
\text { Mortality: } 0 \%\end{array}$ & $\begin{array}{l}3 \text { patients post-mRNA } \\
\text { vaccination } \\
\text { Well tolerated } \\
\text { No allograft rejection }\end{array}$ \\
\hline $\begin{array}{l}\text { Ahearn et al. [32] } \\
\text { US-Los Angeles } \\
\text { 02/2020-02/2021 }\end{array}$ & $\begin{array}{l}\text { BAM (33) } \\
\text { C-I (1) }\end{array}$ & $17 \mathrm{KT}+17 \mathrm{LT}$ & $\mathrm{n} / \mathrm{a}$ & $\begin{array}{l}\text { Mortality: } 0 \% \\
\text { Hospitalization: } 15 \%\end{array}$ & Programmatic approach \\
\hline $\begin{array}{l}\text { Jan et al. [33] } \\
\text { US-Indiana } \\
2020\end{array}$ & BAM (24) & $\begin{array}{l}19 \mathrm{KT}+3 \mathrm{~K} / \mathrm{P}+1 \mathrm{H} / \mathrm{K} \\
+1 \mathrm{~L} / \mathrm{K}\end{array}$ & 4.7 & $\begin{array}{l}\text { Mean follow-up: } 67 \\
(23-113) \text { days } \\
\text { Hospitalization: } 4 \\
\text { (16.7\%)- } 3 \text { COVID } \\
\text { related, Intensive care- } \\
\text { 2, MV-1 } \\
\text { Mortality: } 1(4.2 \%)- \\
\text { aspergillosis/sepsis }\end{array}$ & Well tolerated \\
\hline $\begin{array}{l}\text { Kutzler et al. [34] } \\
\text { US-Connecticut } \\
\text { 11/2020-02/2021 }\end{array}$ & BAM (18) & $15 \mathrm{KT}+2 \mathrm{LT}+1 \mathrm{HT}$ & 5 & $\begin{array}{l}\text { Hospitalization } 3(17 \%) \text { : } \\
\text { 2-bacterial pneumonia, } \\
\text { 1- AKI }\end{array}$ & Well tolerated \\
\hline $\begin{array}{l}\text { Klein et al. [35] } \\
\text { US-Rhode Island } \\
03 / 2020-04 / 2021\end{array}$ & $\begin{array}{l}\text { BAM (15) } \\
\text { B-E (1) } \\
\text { C-I (3) }\end{array}$ & $20 \mathrm{KT}$ & $\mathrm{n} / \mathrm{a}$ & $\begin{array}{l}\text { Mortality: } 0 \% \\
\text { MV: } 0 \% \\
\text { Hospitalization: } 15 \%\end{array}$ & $\begin{array}{l}\text { Racial disparity noted for } \\
\text { antibody therapy } \\
\text { Programmatic approach } \\
\text { Lower need to adjust/ } \\
\text { lower IS }\end{array}$ \\
\hline $\begin{array}{l}\text { Del Bello et al. [36] } \\
\text { France-Toulouse } \\
\text { 03/2020-04/2021 }\end{array}$ & $\begin{array}{l}\text { BAM (5) } \\
\text { B-E (9) } \\
\text { C-I (2) }\end{array}$ & $\begin{array}{l}12 \mathrm{KT}+1 \mathrm{~K} / \mathrm{P}+1 \mathrm{~K} / \mathrm{L} \\
+2 \mathrm{HT}\end{array}$ & $\mathrm{n} / \mathrm{a}$ & $\begin{array}{l}\text { Mean follow-up: } 39 \\
(10-74) \text { days } \\
1(6 \%) \text { required supple- } \\
\text { mental } \mathrm{O}_{2} \\
\text { MV: } 0 \% \\
\text { Mortality: } 0 \%\end{array}$ & $\begin{array}{l}\text { Well tolerated } \\
\text { All patients were initially } \\
\text { hospitalized: no read- } \\
\text { mission }\end{array}$ \\
\hline
\end{tabular}

$K T$, kidney transplant; $L T$, liver transplant; $H T$, heart transplant; $K / P$, kidney/pancreas transplant; $H / K$, heart/kidney transplant; $L / K$, liver/kidney transplant; $P$, pancreas transplant; $C$-I, casirivimab-imdevimab; $B A M$, bamlanivimab; $B$ - $E$, bamlanivimab-etesevimab; $U S$, United States; $E D$, emergency department; $M V$, mechanical ventilation; $A K I$, acute kidney injury; $C O V I D$, coronavirus disease; $H T N$, hypertension; $I S$, immunosuppression; d, days; MATRx, monoclonal antibody Rx Team; $O_{2}$, oxygen

care, and there were no reported direct COVID-19 or monoclonal antibody associated death during a 28-30day follow-up period post-infusion. Early administration of monoclonal antibody (4 vs. 6 days) was associated with a further lower risk of subsequent ED visit or hospitalization [29••]. Subsequent studies have shown that the presence of multiple comorbidities may influence the need for hospitalization. Even without a direct comparator group, 
these results are encouraging and show significant clinical progress in the outpatient management of COVID-19.

We have seen similar outcomes with our ongoing experience when using monoclonal antibody treatment in SOTRs for post-exposure prophylaxis, for treatment of SOTRs with recurrent episodes of COVID-19, and for treatment of vaccine-breakthrough infections (unpublished). We have also used casirivimab-imdevimab in recipients of solid organs from donors with SARSCoV-2 PCR positivity [39]. While the risk of transmission of SARS-CoV-2 from non-lung tissue is very low, early post-transplant administration of anti-SARS-CoV-2 monoclonal antibody may help prevent not only any risk of donor-derived transmission but also protect the recipient during the immediate post-transplant period from any possible nosocomial or community-acquired COVID-19. This is more important in transplant recipients who were previously unvaccinated, who may not have responded adequately to vaccination, or have a concurrent risk of household exposure from unvaccinated children/adults, or anticipated a prolonged post-transplant course in rehabilitation or nursing home facility.

Vaccination of potential recipients during the pretransplant period as well as all household contacts offers the best possible chance for prevention of COVID-19 during the post-transplant period. Considerable variations occur in the community prevalence of COVID-19 and rates of acceptance of SARS-CoV-2 vaccination. Various strategies like mandating vaccination in all transplant candidates can increase its rates of acceptance, but it has not become the standard practice across all transplant centers. A subset of patients with the acute decompensated fulminant disease, who are unable to be fully vaccinated pre-transplant, patients who require retransplantation, and patients with various auto-immune disorders on pre-transplant immunosuppression would be at higher risk of acquiring community-onset COVID-19 immediate post-transplantation, especially in the setting of high rates of community prevalence. Even though vaccinated, household or other close contacts can have very mild or asymptomatic SARS-CoV-2 infection, it can be transmitted to a susceptible host [40]. A subset of SOTRs will not have a significant immunological response even after multiple doses of vaccination $[10,11 \bullet \bullet, 12]$. These patients will be ideal candidates for pre-exposure prophylaxis to minimize any morbidity and mortality associated with COVID-19 as well as to preserve graft function. Sotrovimab and AZD 7442 (combination of long-acting tixagevimab and cilgavimab) have been modified to provide extended half-life in humans, making them interesting targets for potential long-acting pre-exposure prophylaxis [https://www.ema.europa.eu/en/documents/ referral/sotrovimab-also-known-vir-7831-gsk4182136covid19-article-53-procedure-assessment-report_en.pdf. Accessed October 20, 2021] [40]. Synergy with emergent oral anti-viral agents like molnupiravir may offer another outpatient treatment modality in the future in certain pre-determined patients with multiple risk factors and/ or suspected high viral loads. Clinical trials of synergy with high dose extended half-life monoclonal antibodies and other anti-viral agents for patients hospitalized with severe COVID-19 are underway.

Successful administration of monoclonal antibodies requires a programmatic operational response which includes rapid diagnosis, efficient communication between patients and transplant care providers, pre-emptive education of SOTRs regarding availability of various prevention and treatment options, and easily accessible sites for

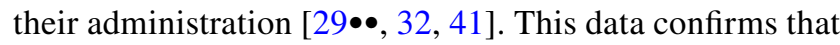
timely and early administration of monoclonal antibodies is associated with a significantly lower risk of hospitalization. The providers should be aware of and address any possible disparities involving underrepresented populations when providing these potentially lifesaving options $[35,42]$.

\section{Conclusion}

Anti-SARS-CoV-2 monoclonal antibodies are currently the only FDA-authorized treatment option for outpatient management of COVID-19. Overall, the early results from a diverse population of SOTRs are encouraging with improvement in outcomes including prevention of hospitalization or deaths related to COVID-19. Successful administration of anti-SARS-CoV-2 monoclonal antibodies requires a multidisciplinary team approach, effective communication between patients and providers, awareness of circulating variants, acknowledgement of various biases affecting treatment, and close monitoring for efficacy and tolerability.

\section{Delarations}

Conflict of Interests A.D. has received an institutional grant from Regeneron, Tetraphase, for work outside this submission. R.R. is the principal investigator of research funded by Regeneron, Roche, Gilead (all funds provided to his institution), and is a member of the Data Safety Monitoring Board of Novartis, on projects not directly related to this submission. 


\section{References}

Papers of particular interest, published recently, have been highlighted as:

- Of importance

$\bullet$ Of major importance

1. Hadi YB, Naqvi SFZ, Kupec JT, Sofka S, Sarwari A. Outcomes of COVID-19 in solid organ transplant recipients: a propensitymatched analysis of a large research network. Transplantation. 2021;105(6):1365-71. https://doi.org/10.1097/TP.0000000000 003670.

2. Jering KS, McGrath MM, Mc Causland FR, Claggett B, Cunningham JW, Solomon SD. Excess mortality in solid organ transplant recipients hospitalized with COVID-19: a large-scale comparison of SOT recipients hospitalized with or without COVID-19. Clin Transplant. 2021:e14492 https://doi.org/10. 1111/ctr.14492

3. Heldman MR, Kates OS, Safa K, et al.- UW COVID-19 SOT Study Team. Changing trends in mortality among solid organ transplant recipients hospitalized for COVID-19 during the course of the pandemic. Am J Transplant. 2021. https://doi.org/ 10.1111/ajt.16840

4. Vinson AJ, Agarwal G, Dai R, et al. COVID-19 in solid organ transplantation: results of the National COVID Cohort Collaborative. Transplant Direct. 2021;7(11): e775. https://doi.org/10. 1097/TXD.0000000000001234.

5. Centers for Disease Control and Prevention. Interim clinical considerations for use of COVID-19 vaccines currently approved or authorized in the United States. 2021. Available at: https:// www.cdc.gov/vaccines/covid-19/clinical-considerations/covid19-vaccines-us.html. Accessed October 21, 2021.

6. Boyarsky BJ, Werbel WA, Avery RK, et al. Antibody response to 2-dose SARS-CoV-2 mRNA vaccine series in solid organ transplant recipients. JAMA. 2021;325(21):2204-6. https://doi. org/10.1001/jama.2021.7489.

7. Rabinowich L, Shibolet O, Katchman H. Effectiveness of SARS-Cov-2 vaccination in liver transplanted patients: time for comprehensive data analysis. J Hepatol. 2021: S01688278(21)02102-4. https://doi.org/10.1016/j.jhep.2021.09.037

8. Aslam S, Danziger-Isakov L, Mehra MR. COVID-19 vaccination immune paresis in heart and lung transplantation. J Heart Lung Transplant. 2021;40(8):763-6. https://doi.org/10.1016/j.healun. 2021.04.018.

9.- Qin CX, Moore LW, Anjan S, et al. Risk of breakthrough SARS-CoV-2 infections in adult transplant recipients. Transplantation. 2021. https://doi.org/10.1097/TP.0000000000003907 This study highlights the clinical implications of sub-optimal measured antibody response to 2 dose mRNA vaccine on SOTRs, breakthrough infections, and associated morbidity and mortality.

10. Kamar N, Abravanel F, Marion O, Couat C, Izopet J, Del Bello A. Three doses of an mRNA Covid-19 vaccine in solid-organ transplant recipients. N Engl J Med. 2021;385(7):661-2. https:// doi.org/10.1056/NEJMc2108861.

11.• Hall VG, Ferreira VH, Ku T, et al. Randomized trial of a third dose of mRNA-1273 vaccine in transplant recipients. N Engl J Med. 2021;385(13):1244-1246. https://doi.org/10.1056/NEJMc 2111462. Provides early evidence and proof of concept supporting the use of additional $3^{\text {rd }}$ dose mRNA vaccine in SOTRs for improving vaccine immunogenicity.

12. Peled Y, Ram E, Lavee J, et al. Third dose of the BNT162b2 vaccine in heart transplant recipients: immunogenicity and clinical experience [published online ahead of print, 2021 Aug
28]. J Heart Lung Transplant. 2021; S1053-2498(21)02481-5. https://doi.org/10.1016/j.healun.2021.08.010

13. Buchwald UK, Pirofski LA. Immune therapy for infectious diseases at the dawn of the twenty-first century: the past, present and future role of antibody therapy, therapeutic vaccination and biological response modifiers. Curr Pharm Des. 2003;9:945-68. https://doi.org/10.2174/1381612033455189.

14. Casadevall A, Dadachova E, Pirofski LA. Passive antibody therapy for infectious diseases. Nat Rev Microbiol. 2004;2:695-703. https://doi.org/10.1038/nrmicro974.

15. Behring EA, Kitasato S. Ueber das zustandekommen der diptherie-immunität und der tetanus-immunität bei thieren. Deutch Med Woch. 1890;49:1113-4.

16. Zhang JS, Chen JT, Liu YX, et al. A serological survey on neutralizing antibody titer of SARS convalescent sera. J Med Virol. 2005;77(2):147-50. https://doi.org/10.1002/jmv.20431.

17. Casadevall A, Pirofski LA. The convalescent sera option for containing COVID-19. J Clin Invest. 2020;130(4):1545-8. https://doi.org/10.1172/JCI138003.

18. DeFrancesco L. COVID-19 antibodies on trial. Nat Biotechnol. 2020;38(11):1242-52. https://doi.org/10.1038/s41587-0200732-8 (Erratum.In:NatBiotechnol.2021Feb;39(2):246).

19. Jiang S, Hillyer C, Du L. Neutralizing antibodies against SARS-CoV-2 and other human coronaviruses [published correction appears in Trends Immunol. 2020 Apr 24;]. Trends Immunol. 2020;41(5):355-359. https://doi.org/10.1016/j.it. 2020.03.007

20. Food and Drug Administration. Fact sheet for healthcare providers: emergency use authorization (EUA) of casirivimab and imdevimab. 2021. Available at: https://www.fda.gov/media/ 145611/download. Accessed October 21, 2021

21. Food and Drug Administration. Fact sheet for healthcare providers: emergency use authorization (EUA) of bamlanivimab and etesevimab. 2021. Available at: https://www.fda.gov/media/ 145802/download. Accessed October 21, 2021

22. Food and Drug Administration. Fact sheet for healthcare providers: emergency use authorization (EUA) of sotrovimab. 2021. Available at: https://www.fda.gov/media/149534/download. Accessed October 21, 2021

23. Casirivimab and Imdevimab [product monograph]. Mississauga, Ontario, Canada: Hoffmann-La Roche Ltd; June 2021. Accessed October 21, 2021

24. Weinreich DM, Sivapalasingam S, Norton T, et al. REGEN-COV antibody combination and outcomes in outpatients with COVID19. N Engl J Med. 2021: NEJMoa2108163. doi: https://doi.org/ 10.1056/NEJMoa2108163

25. O'Brien MP, Forleo-Neto E, Musser BJ, et al. Subcutaneous REGEN-COV antibody combination for COVID-19 Prevention. N Engl J Med. 2021;385(13):1184-95. https://doi.org/10.1056/ NEJMoa2109682.

26. Gottlieb RL, Nirula A, Chen P, et al. Effect of bamlanivimab as monotherapy or in combination with etesevimab on viral load in patients with mild to moderate COVID-19: a randomized clinical trial. JAMA. 2021;325(7):632-44. https://doi.org/10.1001/jama. 2021.0202.

27. Cohen MS, Nirula A, Mulligan MJ, et al. Effect of bamlanivimab vs placebo on incidence of COVID-19 among residents and staff of skilled nursing and assisted living facilities: a randomized clinical trial. JAMA. 2021;326(1):46-55. https://doi.org/10. 1001/jama.2021.8828.

28.• Yetmar ZA, Beam E, O'Horo JC, Ganesh R, Bierle DM, Brumble L, Seville MT, Razonable RR. Monoclonal antibody therapy for COVID-19 in solid organ transplant recipients. Open Forum Infect Dis. 2021;8(6):ofab255. https://doi.org/10.1093/ofid/ ofab255. This is the largest study so far in the use of antiSARS-CoV-2 monoclonal antibodies in SOTRs showing both 
efficacy in reducing risk of hospitalization, mortality as well as safety.

29.•• Dhand A, Lobo SA, Wolfe K, Feola N, Lee L, Nog R, Chen D, Glicklich D, Diflo T, Nabors C. Casirivimab-imdevimab for treatment of COVID-19 in solid organ transplant recipients: an early experience. Transplantation. 2021;105(7):e68-e69. https://doi.org/10.1097/TP.0000000000003737. Largest study for treatment of COVID-19 using casirivimab-imdevimab in SOTRs, with no evidence of progression of disease, $0 \%$ mortality and no severe adverse events.

30. Dhand A, Lobo SA, Wolfe K, Feola N, Nabors C. Bamlanivimab for treatment of COVID-19 in solid organ transplant recipients: early single-center experience. Clin Transplant. 2021;35(4):e14245. https://doi.org/10.1111/ctr.14245

31. Liu EC, Lee JH, Loo A, Mazur S, Sultan S, Aull M, Lee JB, Muthukumar T, Hartono C. Casirivimab-imdevimab (REGNCOV2) for mild-to-moderate SARS-CoV2 infection in kidney transplant recipients. Kidney Int Rep. 2021. https://doi.org/10. 1016/j.ekir.2021.08.032

32. Ahearn AJ, Maw TT, Mehta R, Emamaullee J, Kim J, Blodget E, Kahn J, Sher L, Genyk Y. A programmatic response, including bamlanivimab or casirivimab-imdevimab administration, reduces hospitalization and death in COVID-19 positive abdominal transplant recipients. Transplantation. 2021. https://doi.org/ 10.1097/TP.0000000000003953

33. Jan MY, Sayegh SE, Webb HT, Adebiyi O, Anderson MD, Mishler DP, Yaqub MS, Taber T, Sharfuddin AA. Bamlanivimab for mild to moderate COVID-19 in kidney transplant recipients. Kidney Int Rep. 2021;6(9):2468-71. https://doi.org/10.1016/j. ekir.2021.06.012.

34. Kutzler HL, Kuzaro HA, Serrano OK, Feingold A, Morgan G, Cheema F. Initial experience of bamlanivimab monotherapy use in solid organ transplant recipients. Transpl Infect Dis. 2021:e13662.https://doi.org/10.1111/tid.13662

35. Klein EJ, Hardesty A, Vieira K, Farmakiotis D. Use of antispike monoclonal antibodies in kidney transplant recipients with COVID-19: efficacy, ethnic and racial disparities. Am J Transplant. 2021. https://doi.org/10.1111/ajt.16843
36. Del Bello A, Marion O, Vellas C, Faguer S, Izopet J, Kamar N. Anti-SARS-CoV-2 monoclonal antibodies in solid-organ transplant patients. Transplantation. 2021;105(10):e146-7. https:// doi.org/10.1097/TP.0000000000003883.

37. SARS-CoV-2 variants of concern and interest and susceptibility to anti-SARS-CoV-2 monoclonal antibodies available at https://www.covid19treatmentguidelines.nih.gov/tables/tablea. Accessed October 21, 2021

38. Dhand A, Gass A, Nishida S, et al. Successful transplantation of organs from a deceased donor with early SARS-CoV-2 infection. Am J Transplant. 2021:https://doi.org/10.1111/ajt.16706. https:// doi.org/10.1111/ajt.16706

39. Lael M Yonker, Julie Boucau, James Regan, et al. Virologic features of SARS-CoV-2 infection in children, The Journal of Infectious Diseases, 2021; jiab509, https://doi.org/10.1093/infdis/jiab509

40. Yueh-Ming Loo, Patrick M. McTamney, Rosalinda H. Arends et al. AZD7442 demonstrates prophylactic and therapeutic efficacy in non-human primates and extended half-life in humans. Available at: medRxiv 2021.08.30.21262666; doi: https://doi. org/10.1101/2021.08.30.21262666. Accessed October 21, 2021

41. Razonable RR, Aloia NCE, Anderson RJ, et al. A framework for outpatient infusion of antispike monoclonal antibodies to highrisk patients with mild-to-moderate coronavirus disease-19: the Mayo clinic model. Mayo Clin Proc. 2021 May;96(5):1250-61. https://doi.org/10.1016/j.mayocp.2021.03.010.

42. Bierle DM, Ganesh R, Wilker CG, et al. Influence of social and cultural factors on the decision to consent for monoclonal antibody treatment among high-risk patients with mild-moderate COVID-19. J Prim Care Community Health. 2021;12:21501327211019282. https://doi.org/10.1177/21501 327211019282

Publisher's Note Springer Nature remains neutral with regard to jurisdictional claims in published maps and institutional affiliations. 